\title{
ZnO doping profile effect on CIGS solar cells efficiency and parasitic resistive losses based on cells equivalent circuit
}

\begin{abstract}
The window layer of the CIGS thin film solar cells plays the role of transparent front contact and the $n$-side of pn-heterojunction. Thus the variation of window layers electrical and optical properties can affect the cell performance. Properties of Al-doped Zinc oxide $(\mathrm{ZnO})$ thin film as most common used window layer for CIGS solar cells were studied via simulation using the simulation program called SCAPS-1D. This study is aimed to find the effect of $\mathrm{ZnO}$ layer doping profile on cell performance. It is found that increasing $\mathrm{Al}$-content up to $5 \%$ in $\mathrm{ZnO}$ layer will lead to increasing the cell efficiency and will decrease the cell series and shunt resistance.
\end{abstract}

Keyword: CIGS; SCAPS-1D; Thin film solar cells; Window layer; Zinc oxide 